\title{
Survey of Rumen Impaction in Goat from Katsina Metropolis, Katsina State, Nigeria
}

\author{
${ }^{1}$ YUSUF, A; ${ }^{1 *}$ ARUWAYO, A; ${ }^{2}$ MAIGANDI, SA \\ ${ }^{1}$ Department of Animal Science, Faculty of Agriculture and Agricultural Technology, Federal University Dutsin-ma, P.M.B 5001, Post \\ Code 821221, Dutsinma, Katsina State. \\ ${ }^{2}$ Department of Animal Science, Usmanu Danfodiyo University, Post code 840212, Sokoto \\ *Corresponding Author Email: aruwayoadebayo@gmail.com
}

\begin{abstract}
The study was conducted to investigate rumen impaction in goats slaughtered at Katsina Metropolitan Abattoir by administering 147 questionnaires and making weekly visits to the abattoir for information retrieval for eleven weeks. In addition, live-weights of sampled animals, weight of rumen contents and empty rumen were determined. The data indicated that $60 \%$ of the animal keepers allow their animals to scavenge on refuse and majority (93\%) of the respondents observed some effects of rumen infection, which include death of the animals (34\%). The result revealed that the problem was more common among the age range of 16 and 18 months of age and that sex also has effect on the rate of impaction occurring more in females. Types and quantity of non-degradable materials in the affected animals were identified and polythene materials occurred more. Frequency of non-degradable materials was also observed in goats. The study recommends cleanup of the environment in that, it will substantially reduce foreign bodies syndrome in goats, proper feeding, addition of mineral constituents in the diet, hence there is need for state legislature to enforce proper disposal of non-degradable synthetic polythene materials to make the environment safe for ruminants.
\end{abstract}

\section{DOI: https://dx.doi.org/10.4314/jasem.v22i5.16}

Copyright: Copyright $\left({ }_{0} 2018\right.$ Yusuf et al. This is an open access article distributed under the Creative Commons Attribution License (CCL), which permits unrestricted use, distribution, and reproduction in any medium, provided the original work is properly cited.

Dates: Received: 08 March 2018; Revised: 10 April: 2018; Accepted: 19 April 2018

Keywords: Ruminant, pasture, rumen, polythene, goat, scavenge

In subsistent production systems, in which the primary purpose is to meet family needs, many urban families indeed keep a few chickens, two to three sheep and goats for occasional consumption. Little or no investment is made into the feeding or health care of the animals. The animals scavenge for a large part of their required feed, but are supplemented with household food processing wastes and therefore, performance is poor and mortality rate is high (Maxwell, 1994). The relatively non availability of pasture in some parts of northern Nigeria during the dry season causes the malnourished and mineral deficient ruminant animals to scavenge on widely available used and improperly disposed polythene bags and other household wastes that litter, which induces rumen impaction (Muhammad and Muhammed, 2007). Polythene bags induced rumen impaction is fast becoming a major problem in ruminant animal production. This is due to improper disposal of used polythene bags (Muhammad, 2002). They are thrown into rubbish dumps, roadsides and virtually everywhere, littering the environment thereby posing health hazards to ruminant that are left to graze around villages, towns and cities. Most of the products wrapped in polythene bags increase their palatability because some are spicy, salty, sugary or oily (Muhammad, 2002). Underfed animals are therefore attracted to feed on them because pasture is not usually available during the dry season. These biologically non-degradable polythene materials which may include shreds of bailing twine, leather, ropes and rags, when ingested by animals get lodged in the rumen, thereby occupying the ruminal space interfering with normal physiological function of the rumen (Muhammad, 2002). Non-biodegradable (polythene bags) stray the animals foraging them (Tutorvista, 2010). Anonymous (2010) reported that eating polythene bags resulted in death of 100 ruminant animals (goat, sheep and cattle) per day in India, and as much as $35 \mathrm{~kg}$ of polythene was found in the rumen of one of the dead cows. Globally, about 10,000 animals are salvaged annually due to polythene bags consumption (Buzzle, 2010). Many animals ingest polythene bags considering them as food which results in weight loss, high mortality rates and premature slaughter of sick animals. The ingested polythene bag remains intact even after the death and decomposition of the animal's body (Buzzle, 2010).

The present study was designed to find out the type and quantity of non-degradable materials obtainable in the rumen of goats slaughtered in Katsina metropolitan abattoir and their implication on the welfare of the animals. The frequency of occurrence of non-

*Corresponding Author Email: aruwayoadebayo@gmail.com 
biodegradable materials based on age, species and sex was also assessed.

\section{MATERIALS AND METHODS}

Study site: The study site (Katsina main abattoir) is located in Kofar Kwaya in Katsina metropolis of Katsina Local Government Area, Katsina state. The State lies between $12^{\circ} 15 \mathrm{~N}$ and $7^{\circ} 3 \mathrm{E}$ in the Sudan Savannah zone of Nigeria (Nkromah, 2007) with hot and dry climatic conditions for most of the year. The hottest months are March to May with temperatures ranging from $23^{\circ} \mathrm{C}$ to $42^{\circ} \mathrm{C}$. The annual rainfall varies from $700 \mathrm{~mm}-1000 \mathrm{~mm}$ and rainy season is usually from June to September. The people of Katsina State are mainly farmers, petty traders and civil servants (Katsina State Diary, 2002).

Data Collection and Experimental Design: Daily records of the goats slaughtered at the abattoir were obtained and recorded based on their sex and age. The weights of the animals to be slaughtered were determined using a Salter scale, while the age was determined by dentition method (Vatta et al., 2005). Three animals each aged 6,12 and 18 month from male and female goats were selected for the determination of rumen impaction on weekly basis for a period of eleven weeks. The experiment was conducted in a 3 by 2 factorial arrangement in a Completely Randomized Design (CRD). The factors considered were age (6, 12 and 18 months) and sex (male and female). A total of 150 structured questionnaires were administered to livestock keepers to gather information on the impact of nonbiodegradable materials on the welfare of the animals.

Evaluation of Rumen Contents: After slaughter and evisceration, the rumen with its contents were weighed as (W1) and reweighed after emptying as (W2). The non-degradable materials were separated by floating them in water and later were sieved, the weight of the materials determined was (W3), while that of degradable was (W4) which was subtracted from (W3). The weight of the empty rumen was computed by subtracting (W2 from W1), furthermore, the nondegradable materials were separated into different categories. Polythene bags were recorded as 1, metallic objects (nails, spoons and needles) were recorded and coded as 2 , and was recorded and coded as 3. Degradable materials were separated into fibre, woody materials, and textile materials and were recorded and coded as 4 and others were recorded 5, and were expressed in percentage of the total nonbiodegradable materials.
Statistical Analysis: Statistical Correlation analysis was computed by comparing live weight with the rate of impaction, weight of empty rumen with the rate of impaction and weight of rumen contents with the rate of impaction. This was done for both species and both sexes. Data obtained from structured questionnaires were analyzed using descriptive statistics such as frequencies and percentages.

\section{RESULTS AND DISCUSSION}

The response on scavenging habit of goats surveyed is shown in Table 1 . The result obtained revealed that majority $(60 \%)$ of the respondent' animals scavenge, and most of them $61 \%$ feel unsatisfactory. Those that consume polythene material contributed $68 \%$. Majority of the respondents $(93 \%)$ observed impact, others did not. Types of impact observed were emaciation, loss of appetite, poor performance and death. Death $(34 \%)$ and poor performance $(25 \%)$ contributed $(59 \%)$ while emaciation accounted for $(21 \%)$ and loss of appetite $(20 \%)$.

The relationship of sex, age, and live-weight, weight of empty rumen, weight of rumen contents and weight of non-biodegradable materials in goat is shown in Table 2. This Table showed that the correlation coefficients of live weight, empty rumen, rumen contents and weight of non-biodegradable materials in goat sex and age. Sex when compared with age, it showed no relation $\left(r^{2}=0.00\right)$. It was shown that there was a highly significant weak positive relation between sex and live weight $\left(r^{2}=0.399\right)$, there was weak positive relationship between weight of empty rumen and sex $\left(r^{2}=0.235\right)$. A highly significant weak positive relationship existed between sex and weight of empty rumen contents $\left(\mathrm{r}^{2}=0.398\right)$. There was also a highly significant weak positive correlation $\left(\mathrm{r}^{2}=\right.$ 0.360 ) between sex and weight of non-degradable materials. The table showed that there was highly significant and strong positive relationship between age and live weight $\left(r^{2}=0.499\right)$, while between age and empty rumen, the relationship was significantly weak positive relationship $\left(r^{2}=0.274\right)$. In the case of age against weight of rumen contents, there was weak positive relationship $\left(r^{2}=0.195\right)$. Also there was weak positive relationship between age and weight of nondegradable materials $\left(r^{2}=0.16\right)$, but a highly significant and weak positive correlation existed between live weight and sex $\left(r^{2}=0.399\right)$. Table 3 revealed that out of the 66 goats examined after slaughter for the presence of non-degradable materials in the study area, $35 \%$ of them ate plastic while scavenging, $2 \%$ for fibre and $1 \%$ each of metal and sand. 
Table 1: Respondents based on scavenging on dump refuse by the animals in Katsina

\begin{tabular}{|c|c|c|}
\hline Variables & Frequency & Percentage \\
\hline \multicolumn{3}{|c|}{ Do your animals scavenge? } \\
\hline Yes & 88 & 60 \\
\hline No & 59 & 40 \\
\hline Total & 147 & 100 \\
\hline \multicolumn{3}{|c|}{ Feelings on Scavenging } \\
\hline Satisfactory & 34 & 39 \\
\hline Unsatisfactory & 54 & 61 \\
\hline Total & 88 & 100 \\
\hline \multicolumn{3}{|c|}{ Do you consume polythene materials } \\
\hline Yes & 100 & 68 \\
\hline No & 47 & 32 \\
\hline Total & 147 & 11 \\
\hline \multicolumn{3}{|c|}{ Do you observe impact } \\
\hline Yes & 94 & 93 \\
\hline No & 7 & 32 \\
\hline Total & 101 & 100 \\
\hline \multicolumn{3}{|c|}{ Types of impact observed } \\
\hline Emaciation & 22 & 21 \\
\hline Loss of appetite & 20 & 20 \\
\hline Poor performance & 25 & 25 \\
\hline Death & 35 & 34 \\
\hline Total & 101 & 100 \\
\hline
\end{tabular}

Table 2: Correlation coefficients of sex, age, live-weight, empty rumen, rumen contents and weight of non-biodegradable materials in goat sex and age.

\begin{tabular}{lllllll}
\hline Parameters & Sex & Age & LW & ER & RC & NBDM \\
\hline Sex & 1 & & & & \\
Age & 0.00 & 1 & & & \\
Liveweight & $0.399^{* *}$ & $0.499^{* *}$ & 1 & & \\
Empty Rumen & 0.235 & $0.274^{* *}$ & $0.342^{* *}$ & 1 & & \\
Rumen Contents & $0.398^{* *}$ & 0.195 & $0.601 * *$ & $0.638^{*}$ & 1 & \\
NBDM & $0.360^{* *}$ & 0.106 & $0.395^{* *}$ & 0.155 & 0.159 \\
**Correlation is highly significant at the 0.01 level (2-tailed); *Correlation is significant \\
at the 0.05 level (1-tailed) NBDM: Signifies Non-Biodegradable Materials.
\end{tabular}

Table 3: Proportions (\%) of different non-degradable materials found in goats slaughtered in the study area.

\begin{tabular}{lll}
\multicolumn{3}{c}{ slaughtered in the study area. } \\
\hline & Frequency & Percentage $(\%)$ \\
\hline Plastic & 23 & 35 \\
Fibre & 2 & 3 \\
Metal & 1 & 1.5 \\
Sand & 1 & 1.5 \\
WNDM & 39 & 59 \\
Total & 66 & 100 \\
\hline
\end{tabular}

Table 4: Mean Liveweight, Weights of Rumen Contents, Empty Rumen and Non Degradable Materials in Goats slaughtered at Katsina Abattoir

\begin{tabular}{llllllll}
\hline \multicolumn{7}{c}{ Male(Buck) } & \multicolumn{5}{c}{ Female( Doe) } \\
\hline $\begin{array}{l}\text { Age in } \\
\text { Month }\end{array}$ & 6 & 12 & 18 & 6 & 12 & 18 & SE \\
LW & 13.3 & 17.27 & $21.73^{\mathrm{c}}$ & 18.27 & 23.82 & 27.18 & 0.876 \\
RC & $1.26^{\mathrm{c}}$ & $1.11^{\mathrm{c}}$ & $2.48^{\mathrm{b}}$ & $2.40^{\mathrm{b}}$ & $3.35^{\mathrm{b}}$ & $2.74^{\mathrm{b}}$ & 0.184 \\
ER & $0.45^{\mathrm{c}}$ & $0.63^{\mathrm{b}}$ & $0.62^{\mathrm{b}}$ & $0.56^{\mathrm{b}}$ & $0.77^{\mathrm{b}}$ & $0.70^{\mathrm{b}}$ & 0.028 \\
NBDM & 0.082 & $0.05^{\mathrm{b}}$ & $0.01^{\mathrm{c}}$ & $0.25^{\mathrm{b}}$ & $0.22^{\mathrm{b}}$ & $0.45^{\mathrm{b}}$ & 0.046 \\
\hline
\end{tabular}

Means followed by the same letter superscript within the same rows are statistically not significantly different $(P<0.05) . L W=$ Live weight in $\mathrm{kg} ; R C=$ Weight of rumen contents in $\mathrm{kg} ; E R=$ Weight of empty rumen in $\mathrm{kg} ; \mathrm{NBDM}=$ Non-biodegradable materials in $\mathrm{kg}$.

A highly significant and strong correlation was observed $\left(r^{2}=0.499\right)$ between live weight and age. However, in the case of empty rumen, a highly significant weak positive relationship $\left(r^{2}=0.342\right)$ existed. In the case of relationship between live weight and weight of rumen contents, a highly significant and strong relationship $\left(\mathrm{r}^{2}=0.601\right)$ existed. While the case of weight of non-biodegradable and live weight, there was a highly significant weak positive relationship $\left(\mathrm{r}^{2}=0.395\right)$. The table 2 also revealed that there was a weak relationship between weight of empty rumen and $\operatorname{sex}\left(\mathrm{r}^{2}=\right.$ 0.235 ), but between weight of empty rumen and age there existed a significantly weak positive relationship $\left(\mathrm{r}^{2}=0.274\right)$. Also a highly significant weak positive relationship $\left(\mathrm{r}^{2}=0.342\right)$ existed between live weight and weight of empty rumen. In the case of weight of empty rumen against weight of rumen contents, a highly significant positive relationship existed $\left(\mathrm{r}^{2}=\right.$ 0.638), while in the case of weight of empty rumen and weight of nondegradable materials, the relationship is a weak positive $\left(\mathrm{r}^{2}=\right.$ 0.155). The weight of rumen contents and weight of nondegradable materials has a weak positive relationship $\left(\mathrm{r}^{2}=0.159\right)$. Table 4 reveals that there was no significant difference between the average live weight of 12 month buck $(17.27 \mathrm{~kg})$ and 18 month buck $(21.73 \mathrm{~kg})$ at $(\mathrm{P}>0.05)$ but a significant difference existed when 6 month buck (13.36kg) was compared with month age $(17.27 \mathrm{~kg})$ at $(\mathrm{P}<0.05)$ and a highly significant difference existed when it was compared with 18 month buck $(21.73 \mathrm{~kg})$ at $(\mathrm{P}<0.05)$. Results on the weight of rumen contents of 6 month buck $(1.26 \mathrm{~kg})$ and that of 12 month $(1.11 \mathrm{~kg})$ were statistically the same, meaning that they are not significantly different at $(\mathrm{P}>0.05)$. But it reveals that there was a highly significant difference between the weight of rumen contents in 18 month buck $(2.48 \mathrm{~kg})$ at $(\mathrm{P}<0.05)$ when it was compared with that of 6 month and 12 month bucks. 
The weight of empty rumen in 12 month buck $(0.63 \mathrm{~kg})$ and that of 18 month $(0.62 \mathrm{~kg})$ were significantly the same $(\mathrm{P}>0.05)$. While in 6 month buck the weight of empty rumen $(0.45 \mathrm{~kg})$ differs significantly at $(\mathrm{P}<0.05)$ from that of 6 month and 12 month bucks. The results of weight of non-degradable materials in 6 month buck $(0.05 \mathrm{~kg})$ and that of 18 month $(0.05 \mathrm{~kg})$ were significantly the same $(\mathrm{P}>0.05)$. Table 4 reveals that there was no significant difference between the live weight of 12 month buck (17.27kg) and 18 month buck $(21.73 \mathrm{~kg})$ at $(\mathrm{P}>0.05)$. But a significant difference existed when 6 month buck $(13.36 \mathrm{~kg})$ was compared with 12 month age $(17.27 \mathrm{~kg})$ at $(\mathrm{P}<0.05)$ and a highly significant difference existed when it was compared with 18 month buck $(21.73 \mathrm{~kg})$ at $(\mathrm{P}<0.05)$.

Results on the weight of rumen contents of 6 month buck $(1.26 \mathrm{~kg})$ and that of 12 month $(1.11 \mathrm{~kg})$ were statistically the same, meaning that they are not significantly different at $(\mathrm{P}>0.05)$. But it reveals that there was a highly significant difference between the weight of rumen contents in 18 month buck $(2.48 \mathrm{~kg})$ at $(\mathrm{P}<0.05)$ when it was compared with that of 6 month and 12 month bucks. The weight of empty rumen in 12 month buck $(0.63 \mathrm{~kg})$ and that of 18 month $(0.62 \mathrm{~kg})$ were significantly the same $(\mathrm{P}>0.05)$. While in 6 month buck the weight of empty rumen $(0.45 \mathrm{~kg})$ differs significantly at $(\mathrm{P}<0.05)$ from that of 6 month and 12 month bucks. The result on weight of nondegradable materials in 6 month buck $(0.05 \mathrm{~kg})$ and that of 18 month $(0.05 \mathrm{~kg})$ were significantly the same $(\mathrm{P}>0.05)$. But a highly significant difference existed when weight of non-degradable materials in 12 month buck $(0.01 \mathrm{~kg})$ was compared with those of 6 and 18 month bucks at $(\mathrm{P}<0.05)$. The table reveals that there was no significant statistical difference between live weights of 6 month doe $(18.27 \mathrm{~kg})$ and that of 12 month $(23.82 \mathrm{~kg})$ at $(\mathrm{P}>0.05)$. But, a highly significant statistical difference existed when these live weights were compared with that of 18 month doe $(27.18 \mathrm{~kg})$ at $(\mathrm{P}<0.05)$. There was no significant difference statistically among the weights of rumen contents in 6 month doe $(2.40 \mathrm{~kg})$ and the weight of rumen contents in 12 month doe $(3.35 \mathrm{~kg})$ as well as that of 18 month doe $(2.74 \mathrm{~kg})$ at $(\mathrm{P}>0.05)$. The result on weight of empty rumen in 6 month doe $(0.56 \mathrm{~kg}), 12$ month $(0.77 \mathrm{~kg})$ and 18 month doe $(0.70 \mathrm{~kg})$ indicated that they were statistically similar at $(\mathrm{P}>0.05)$. The result also reveals that the weights of non-degradable materials in 6 month doe $(0.25 \mathrm{~kg}), 12$ month $(0.22 \mathrm{~kg})$ and 18 month doe $(0.45 \mathrm{~kg})$ were statistically similar $(\mathrm{P}>0.05)$.

The research revealed that majority (60\%) of the sheep and goats in the study area allow their animals to scavenge on refuse dump, which makes most of them
(61\%) feel unsatisfactory. This is may be due to nonavailability of pasture during the dry season as reported by Muhammad and Muhammed (2007) that the relatively non-availability of pasture in some parts of northern Nigeria during the dry season predisposes malnourished and mineral deficient ruminant animals to scavenge on widely available and used improperly disposed polythene bags and other household wastes that litter, which induces rumen impaction.

Majority of the respondents interviewed (68\%) admitted that their animals consume polythene materials where almost all of them $(93 \%)$ said that they observed so many impacts among which death occurred as indicated by $34 \%$ of the respondents. Others are emaciation $(21 \%)$ and lack of appetite (20\%) poor performance $(25 \%)$. The findings of the current study is in conformity with the findings of Muhammad (2002) who reported that lodgment of non-degradable materials in the rumen of small ruminants results into weight loss, high mortality rates and premature slaughter of the sick animals. Also Anonymous (2010) reported that eating polythene bags resulted in death of 100 ruminant animals (goat, sheep and cattle) per day in India, and as much as $35 \mathrm{~kg}$ of polythene was found in the rumen of the dead cows.

The result presents higher percentage $(68 \%)$ of nondegradable materials in female animals than in males. This is in conformity with the findings of Igbokwe et al. (2003) who reported a higher prevalence in female animals. This may be associated with increased appetite of female animals due to nutritional demand during pregnancy and lactation. Additionally, female animals are kept longer than the males for breeding and hence predisposition could be more than that of the male animals. The higher incidence of rumen Impaction in females could be due to hormonal changes during pregnancy. The gravid uterus which reduces the rumen space by weight of the foetus. Another reason could be due to ingestion of nonbiodegradable plastic materials, which gets lodged in the rumen thereby compromising the ruminal space and interfering with normal physiological functions of the rumen (Sanni et al., 1998).

On average, the mean of the total number of animals aged 6 month and 18, impaction level is higher than those of 12 month are, and this is in conformity with the findings of Remi et al. (2004) and that of Sanni et al (1995). The reason possible could be due to the economic situation of the sheep and goat keepers, necessitates them to sell mid-aged animals for festives, as such they are liable to remain on the hands of salers for a short period, prior to selling them. 
Frequency Occurrence of Different Non-Degradable Materials in Sheep and number of plastic in the rumen of the two species was 162 . Fibre 3 , hair 2 , paper 2 and leather 30 . The findings with the present study were total cases of plastic in the two species was 74, fibre 8, metal 1 and sand 1 . The findings were different with the findings of Abebe and Nuru (2011) where plastic had 28 , hairball 7 , leather 7 , polythene bags 7 and wire 1 .

The live weights of 6 month and 12 month ram did not show any significant difference but that of 18 month showed great difference, probably it was due to gradual increase in general body structure than the former two age categories. But in the case of weight of non-degradable materials there was significant difference in three age categories of females may be it is because female animals are kept longer than males. This is in conformity with Igbokwe (2003) who reported that female animals are kept for breeding purpose, and hence take longer time than females. Likewise, in female sheep, the live weight of 6 and 12 month there was no significant difference, the difference occurred only in 18 month.

This is because as the animal ages the structure developes giving it more weight. While in the case of weight of non-degradable materials. This difference may be due to location where the animals live and economic situation of the keepers. The live weight of 12 and 18 month buck indicated significant difference over that of 6 month; this is may be of difference in feed requirement level. In the case of non-degradable materials there was no significant difference in 6 , and 18 month. They differ with 12 month only. The live weights of 6 and 12 month doe were similar, i.e. there were no significant difference between them, while a significant difference existed in 18 month doe only. In the case of weight of non-degradable materials it was lowest in 12 month doe and highest in 18 month doe.

This is in agreement with the findings of Roman et al. (2010) who reported that more foreign bodies are found in older animals than the young ones may be due to gradual ingestion of indigestible materials over the prolonged period of time.

Conclusion: The study revealed that goats within the study area scavenged due to scarcity of feeds and ingests non-degradable materials which impact negatively on the welfare and productivity of the animals. The study therefore recommends cleanup of the environment as this will substantially reduce foreign body syndrome in goats and aid their proper feeding that will engender improved productivity.

\section{REFERENCES}

Maxwell, DG (1994). The Household Logic of Urban Farming in Kampala. In Cities Feeding People; an Examination of Urban Agriculture in East Africa. International Development Research Centre Ottawa, Canada. Pp. 146.

Muhammad, AK; Muhammad, IR (2007). Fatal Polythene Bag Rumen Impaction in Cattle at Shika - Zaria, Nigeria. Research Journal of Animal Science.

Muhammad, AK (2002). Common Health Problems of Small Ruminants and their Control. National Animal Production Rersearch Institute, A. B. U, Shika - Zaria.

Tutorvista, 2010. Introduction to Non-biodegradable Materials. Retrieved on $05-11-2010$.

Anonymous, 2010. Victorian Litter Action Alliance: Why Plastic Bags Are a Problem. Retrieved on 15 - 09- 2010.

Buzzle, A (2010). Environmental Pollution: The Harmful Effects of Plastic Bags. An article Published by Buzzle.com. Retrieved on $07-10$ $-2010$

Nkromah, G (2007). "Nigeria Fastened with Nails" Al - Ahram Weekly Online.Al - Ahram Weekly. Retrieved on 24-04-2007.

Katsina State Diary (2002). A Publication of the Ministry of Information and Home Affairs.

Vatta, AF; Gumede, SA; Harrison, LJ; Krecek, JS; Letty, BA; Mapeyi, N; Pearson, R. A (2005). Goalkeepers' Veterinary Manual. Onderstepoot Veterinary Institute, Private Bag X05 Onderstepoot 0110, South - Africa.

Igbokwe, IO; Kolo, MY; Egwu, GO (2003). Rumen Impaction in Sheep with Indigestible Foreign Body in the Semi-Arid Region of Nigeria. Small Ruminants Research. 49, 144 - 147. In: Roman, T. and Hiwot, Y. (2010). Occurrence of Rumen Foreign Bodies in Sheep and Goats Slaughtered at the Addis Ababa Municipality Abattoir. Ethiopia Vet. J., 2010, 14(1), 91 100.

Sanni, BD; Gyang, EO; Osinowo, AO; Ema, AN (1995). Studies on Plastic Bag Rumen Impaction in Sheep. $20^{\text {th }}$ Annual Conference of the Nigerian Society of Animal Production, Minna. In: 
Remi-Adewunmi, B. D; Gyang, E. O. and Osinowo, A. O. (2004) Abattoir Survey of Rumen Impaction in Small Ruminants. Nig. Vet. J. 25 (2), 32 - 38 (2004).

Sanni, BD; Gyang, EO; Osinowo, AO (1998). Polythene Bag Induced Rumen Impaction in Small Ruminants: An Environmental Hazard. In: Proceedings of the $25^{\text {th }}$ Anniv. Conf. of the Nigerian Society for Animal Production and the Inaugural Conference of the West African Society for Animal Production, Abeokuta. Pp. 97 - 98.
Remi, YR.; Rao, STV; Naidu, PT; Sunder, NS (2004). Foreign Bodies in Rumen Reticulum of Punganur Cattle, Indian Veterinary Journal, 81 (9:163),

Abebe, F; Nuru, M (2011). Prevalence of Indigestible Foreign Body Ingestion in SmallRuminants Slaughtered at Luna Export Abattoir, East Shoa, Ethiopia. J. Animal and Veterinary Advances 10 (12): 1598 - 11602, 2011. 